\title{
The Relevance of Contextual Generalised Trust in Explaining Individual Immigration Attitudes
}

\author{
Josefina Sipinen (Tampere University) \\ Peter Söderlund (Åbo Akademi University) \\ Maria Bäck (University of Helsinki)
}

\begin{abstract}
This paper measures both individual- and contextual effects of generalised trust on Europeans' attitudes towards immigration. Our data come from round 7 of the European Social Survey (ESS) with which it is possible to measure generalised trust also at the subnational level (NUTS levels). This enables us to capture evident variation in generalised trust within countries. Our main contribution is to test whether two persons who have the same level of generalised trust, but who live in regions differing in mean generalised trust, have different opinions about immigrants. Our results show, first of all, that people with high generalised trust have positive immigration attitudes. Second, living in a high-trusting region does not seem to generally encourage even more positive attitudes towards immigrants. Third, there is, however, another type of contextual effect that moderates the relationship between individual-level generalised trust and pro-immigration attitudes. A high-trusting regional context encourages high-trusting people to develop even more positive attitudes towards immigrants.
\end{abstract}

\section{Introduction}

The increase in ethnic diversity due to immigration has awoken intense discussion about its impact on the future of many European societies. The arrival of refugees in 2015 and the rise of populist parties with negative views on immigration have made these concerns extremely topical. Given that ethnic diversification is a process that is likely to endure, it is important to continue with studies that concern people's opinions of immigration. In this article, we examine whether or not generalised interpersonal trust, which has been found to promote attitudes of tolerance, cooperation and inclusion both at the individual level (Reeskens 2013) and at the community level (Rustenbach 2010), makes people more accepting of immigrants.

It has been shown that individuals who trust "most people in general" are less prejudiced and more accepting of people different from themselves and they are less afraid of empowering new minorities 
(Uslaner 2002; 2010; 2012). Moreover, there is some evidence that societies that are characterized by a high level of generalised trust appear to be more accepting of immigrants: the overall level of trust of a region or country constitutes a "context of reception" where the degree of generalised trust determines how immigrants are perceived (Rustenbach 2010). The underlying idea is that generalised trust alleviates some of the friction that may occur between natives and new ethnic groups. Existing literature provides extensive knowledge of the formation of intergroup attitudes at the individual level (see e.g. Freeman et al. 2013), but we still lack knowledge of how different societal contexts affect these attitudes. One contextual determinant we believe should be further investigated is communitylevel generalised trust.

This study examines the effect of contextual generalised trust on immigration attitudes. By contextual generalised trust we mean individual-level trust aggregated to a higher geographic level. While the effect of contextual trust has received scholarly attention over the years, this study differs from the literature in a number of important ways. First, this study diverges from most other studies by measuring generalised trust at the regional level rather than at the country level. By using data from the European Social Survey that identifies in which subnational unit the respondent lives, we are able to capture evident variation in generalised trust between regions within countries. Second, we distinguish between two different types of contextual effects. One type of contextual effect is when the group context itself influences the attitudes of individual members. In that case, two similar persons who have the same level of generalised trust, but who live in regions differing in mean generalised trust, should have different opinions about immigrants. Another type of contextual effect is when the group context moderates the effect of individual-level trust on the dependent variable. In other words, the strength of the positive effect of individual-level trust on attitudes towards immigrants may differ between low- and high-trust contexts.

The article has the following structure: in the first part, we review existing literature on perceptions on immigration and central hypotheses that have been found to explain them, namely realistic and cultural threat hypotheses. In the second section, the focus is on theoretical and empirical links between generalised trust and immigration attitudes. We also outline how contextual trust matters for the individual-level relationship between trust and immigration attitudes. In the third section, we introduce our data, methods and statistical models. Finally, we summarize our findings and provide our conclusions. 


\section{Understanding Immigration Attitudes}

When aiming to increase the understanding of sources of individuals' anti-immigration attitudes, two main theoretical explanations are offered in the literature, both of which are related to understanding ingroup-attitudes towards outgroups. The first explanation concerns realistic or resource-based feelings of threat felt by the majority. It holds the idea that competition over scarce resources, such as real or imagined threat against economic interests, political advantage, safety or social status of the individual or the group may result in unfavourable attitudes towards outgroups (Blalock 1967; Bobo 1983; Borjas 2001; Mayda 2006; Quillian 1995; Sherif and Sherif 1979; Stephan and Stephan 2000; Stephan et al. 2005). Second, immigrants who belong to different racial and ethnic groups, or have different religious, political, and cultural backgrounds than the natives, may be perceived as a cultural or symbolic threat. This is because natives may feel uncertainty about the consequences that these different characteristics could lead to when it comes to their own way of life (Hainmueller and Hiscox 2007; Stephan and Stephan 2000). These expectations pertain to social identity theory, according to which people's sense of who they are is based on what groups they identify with. Aspiring for positive self-image and positive group distinctiveness, people tend to positively evaluate groups that form the basis of their social identity (Tajfel and Turner 1979). Simultaneously, they often evaluate other groups negatively (Brewer 2001).

An important factor that modifies the majority's anti-immigration attitudes is intergroup contact. Following Allport's (1955) formulation of the "intergroup contact hypothesis", according to which hostile attitudes towards minorities are reduced by e.g. equal status contact between majority and minority groups in the pursuit of common goals (ibid.: 281), scholars have examined intergroup contacts in different empirical settings. A main finding is that contact significantly lowers prejudice and hostility between groups, but only when it happens between persons with equal status and is intimate in nature, such as is the case in friendship relations (McLaren 2003; Pettigrew and Tropp 2011). The contextual setting also plays an important role: individuals who reside in areas where the influx of immigrants is high but no intimate contacts are being established, are more likely to have anti-immigration attitudes. Attitudes and beliefs towards immigration are often important in shaping migration policies, because the public often lacks factual information about e.g. exact fiscal impacts of immigration (Borjas 2001: 126; Hainmueller and Hiscox, 2007; 2010). 


\section{The Impact of Generalised Trust on Immigration Attitudes}

There are several possible mechanisms that connect generalised trust to more positive and accepting views about immigrants and immigration (Uslaner 2002; van der Linden et al. 2017). The paths may be either direct or indirect, and generalised trust may work both at the individual- and the contextual level. Indeed, it must be emphasised that individual generalised trust and contextual generalised trust are separate constructs, as explained below (see Paxton 2007). However, we begin by focusing on the individual-level relationship. Following the literature, our first testable hypothesis concerns the relationship between generalised trust and attitudes towards immigrants at the individual level.

\section{Individual-level Generalised Trust}

There are various stances on whether individual-level generalised trust should be seen as an attitude or a belief (Herreros 2004; Newton 1999; 2001; Stolle 2002; Uslaner 2002), as a judgement or evaluation (Hardin 2001), or even as a decision (Messick and Kramer 2001). Generalised trust, commonly defined as a belief that "most people can be trusted", reflects an individual's positive expectations about the trustworthiness, cooperativeness and helpfulness of others. Thus, it determines the individual's willingness to engage in reciprocal cooperation with others. In contrast to particularised trust, which refers to knowledge- or experience-based trust towards people we are familiar with, or identity-based trust towards people we perceive as similar to us, generalised trust is the belief that people in general, or highly abstract groups of people, are trustworthy. This type of trust is "generalised" because it extends beyond the boundaries of face-to-face interaction and it incorporates people with whom we are not personally familiar. By definition, generalised trust does not exclude outsiders because it is not directed toward a certain group, but people in general (Newton 1999; Stolle 2001; 2002; Uslaner 2002). A certain degree of trust towards people that we are not acquainted with is necessary in modern societies, which are not built on family ties or small communities where everybody is familiar with each other. Trust is the key to productive social exchange, because it significantly lowers transaction costs related to cooperation (Newton 1999).

There is little scholarly consensus on whether generalised trust is grounded in previous experiences or whether it is an innate personal predisposition developed early in life. Stolle (2002) suggests that generalised trust is a result of one or several positive group trust experiences, and it is also more likely built in "bridging" social interactions (see also Hardin 2001). This means that the more diverse the 
individual's own ingroup is, the more likely trusting attitudes are generalised to unknown others. Building (generalised) attitudes of trust is a process of social learning taking place through daily interactions with institutions, family, school and friends (Newton 1999). Building generalised trust or distrust is circular; those who are optimistic about the trustworthiness of others take the risk of cooperating with others more often and, hence, expose themselves to more opportunities to learn about others. Correspondingly, those who are less trusting are likely to avoid contact with people to begin with (Yamagishi 2001). Uslaner (2002) argues, in turn, that once generalised trust is established through socialisation to the values and norms of individuals' close networks and the surrounding environment, it is not easily affected by random cases of deception. Uslaner also suggests that because of their optimism, generalised trusters see opportunities instead of risks in dealing with people who are either unknown or different from themselves.

Generalised trust can be a resource that helps bridging people's differences in a world characterised by ethnic diversification. This is because trusting individuals are more likely to overcome feelings of threat associated with immigration. It is also possible that they feel that cultural differences will not have negative consequences (Herreros and Criado 2009; Rustenbach 2010; Stolle 2002; Uslaner $2002 ; 2010 ; 2012)$. According to Uslaner $(2002,190)$, trusters believe in a culture with shared moral values, which promotes an expansive view of their community. Hence, they do not feel that immigration produces negative outcomes such as intergroup conflicts. They oppose ideas according to which all individuals are not seen as equal members of the society. Instead, they believe in a common culture and the obligation to cooperate with and empower minorities (Uslaner 2002, 190-1; 2012).

Based on the theoretical arguments above, it can be hypothesised that trusters are more willing to engage in personal contact with immigrants. The contacts and friendships that are formed will further increase these individuals' tolerance and positive attitudes towards immigrants (McLaren 2003; Pettigrew and Tropp 2011). Thus, generalised trust may have an indirect impact on immigration attitudes. However, based on their empirical findings, van der Linden, Hooghe, de Vroome and Van Laar (2017) claim that generalised trust and cross-group friendship operate independently from one another and that more trusting individuals are not more inclined to form cross-group friendships than less trusting individuals. Furthermore, cross-group friendships do not lead to generalised trust. If this is the case, then generalised trust will directly make people more inclusive towards immigrants. As suggested by van der Linden et al. (2017), high-trusting individuals seem to include immigrants in 
their broad, encompassing conception of "others" in society without the need of personal relations. To sum up, we formulate the first hypothesis as follows:

H1: The higher an individual's generalised trust, the more positive his or her immigration attitudes.

\section{Contextual Generalised Trust}

According to the "rainmaker hypothesis" generalised trust has the ability to spread from the society to the individual level. Thus, generalised trust can be seen as a collective resource that all individuals may benefit from, regardless of their other individual characteristics, including personal dispositions to trust or distrust (Putnam et al. 2000: 26; van der Meer 2003; Zmerli et al. 2007: 37). Whereas numerous previous studies have focused on the potential consequences of ethnic diversity on social trust (Dinesen and Søderskov 2018), there is less knowledge about how generalised trust may spread out from higher levels (country/region/neighbourhood) on individuals. Countries have a certain number of major socio-economic characteristics (such as social and economic equality and the degree of corruption) that affect policies and, thus, opinions and beliefs (such as social trust) (Rothstein and Uslaner 2005). These characteristics may also vary within the country between regional and local entities. It is reasonable to assume, that the closer the environmental sphere under scrutiny is to the individual the more the contextual aspects that are connected to that environment matter for individual attitudes.

Although between-country differences certainly explain differences when it comes to attitudes towards immigrants, we argue that sub-national (regional) variation in trust may modify individuallevel relationships. The local context, i.e. the type of neighbourhood, city, or region around the individual creates a filter, which may condition different attitudes about immigrants and immigration (Markaki and Longhi 2013). A given region can be seen as an "area of exposure" that reflects peoples' expectations of the general level of trust in their community and exposure to high trust can further translate into positive views of "unknown others", including immigrants, as the rainmaker hypothesis suggests (van der Meer 2003; Zmerli et al. 2007; Rustenbach 2010; Dinesen and Søderskov 2018). Hence, the second hypothesis is as follows: 
H2: The higher the contextual (regional) level of generalised trust, the more positive immigration attitudes an individual will have.

While the overall level of generalised trust constitutes a contextual variable that may affect the relationship between trust and perceptions on immigration at the individual level, we recognise that it is only one of many possible contextual variables. The hypothesis above relates to a contextual or compositional effect, which is said to occur when the aggregate of a person-level characteristic is related to a certain outcome even after controlling for the effect of the individual characteristic in question (Raudenbush and Bryk 2002: 139). Another type of contextual effect is when the context affects the individual-level relationship between two variables. Our third hypothesis deals with the possibility that as the regional mean of generalised trust changes, the effect of generalised trust on attitudes towards immigrants and immigration increases or decreases in magnitude.

Within communities where the overall level of trust is high, there will still be individuals with low trust, and within communities where the overall level of trust is low, there are individuals who are trusting. According to what Bäck and Christensen (2016) call the "sunmaker effect", the effect of individual-level trust is reinforced when the surrounding level of generalised trust is also high. The rationale is that generalised trust spreads more easily in contexts where it is already at a high level, increasing the effects of trust also at the individual level.

Putnam et al. (1993: 177) stress that social capital and cooperation are often self-reinforcing and cumulative, which promotes the collective well-being by creating a "virtuous circle". The same could be argued to hold for the effect of generalised trust on immigration attitudes: a high overall level of generalised trust is expected to create a more tolerant, empathetic and open atmosphere, which reinforces the effect of individual-level trust on immigration attitudes. If one evaluates that others' obligations to reciprocity in the society are high, one can also trust unknown people (Herreros, 2004: 7-14). Therefore, in contexts of high trust, trusting "most people" contains less risk, because most people in the community are engaged in maintaining trust and trustworthiness is a shared moral value. It could be expected that individual-level trust has more concrete consequences in these societies than it has in societies where acting on trust contains higher risks. The third and final hypothesis is:

H3: The effect of individual-level trust is reinforced when the surrounding level of generalised trust is also high. 


\section{Data and Variables}

The analysis of generalised trust and immigration attitudes is based on data from Round 7 (2014/2015) of the European Social Survey. This round includes a rotating module covering multiple questions on attitudes towards immigration. The analysed sample consists of 33,057 respondents from 20 European countries (Austria, Belgium, Czech Republic, Denmark, Estonia, Finland, France, Germany, Hungary, Ireland, Lithuania, Netherlands, Norway, Poland, Portugal, Slovenia, Spain, Sweden, Switzerland and United Kingdom). Between 1,048 and 2,770 interviews were conducted in each country.

\section{Dependent variable}

Six survey questions are used to construct an immigration attitudes index. For each question, respondents gave their answers on a scale from 0 to 10 with 0 indicating the most negative view of the impact of immigration and 10 indicating an extremely positive view.

- Would you say it is generally bad or good for [country]'s economy that people come to live here from other countries?

- Would you say that [country]'s cultural life is generally undermined or enriched by people coming to live here from other countries?

- Is [country] made a worse or a better place to live by people coming to live here from other countries?

- Would you say that people who come to live here generally take jobs away from workers in [country], or generally help to create new jobs?

- Most people who come to live here work and pay taxes. They also use health and welfare services. On balance, do you think people who come here take out more than they put in or put in more than they take out?

- Are [country]'s crime problems made worse or better by people coming to live here from other countries?

Our immigration attitudes index is a composite measure obtained by averaging the six responses. Principal components analysis confirms that the six items load on a single component with item 
loading scores ranging from 0.61 to 0.84 . Cronbach's alpha for the index is 0.85 , indicating good internal consistency. Unfortunately, a large number of respondents in the original sample of 37,623 did not answer all six questions on attitudes towards immigrants. Over 3,000 respondents had one missing value, over 1,000 had two missing values and almost 1,000 had three or more missing values. We choose to include respondents with one or two missing values to increase the sample size. ${ }^{1}$

\section{Generalised Trust: Individual-level and Contextual Predictors}

Generalised trust at the individual level refers to personal assessments of whether people in general are trustworthy, fair and helpful. Our generalised trust index averages responses to the following three questions:

- Generally speaking, would you say that most people can be trusted or that you can't be too careful in life?

- Would you say that most of the time people try to be helpful, or that they are mostly just looking out for themselves?

- Do you think most people would try to take advantage of you if they got a chance, or would they try to be fair?

The responses were coded on a scale from 0 to 10 with higher values indicating higher trust. Principal components analysis (item loadings between 0.79 and 0.84 ) and Cronbach's alpha (0.76) confirm that it is acceptable to regard the scale as a single construct.

When these individual perceptions are aggregated at the group level, they can be used to uncover effects of the group context (i.e. the average levels of helpfulness, trustworthiness and fairness). In the ESS data, a regional variable identifies which NUTS nomenclature each individual belongs. ${ }^{1}$ The rationale behind using the NUTS breakdown of region, rather than employing smaller and even more local environments such as "neighbourhood", is due to data availability. As we have a vast scope of regional units in terms of their population size, our measure of contextual trust only constitutes a rough representation of the respondents" "area of exposure". One fifth of the regions are smaller with between 250,000 and a million inhabitants, while another fifth are larger entities with between three and 17 million inhabitants. People's own views about their community may therefore not correspond with the administrative borders of the regions. However, we argue that reducing the social domain 
from the country level to a closer regional level is an important first step towards understanding mechanisms between different levels of trust and immigration attitudes. For robustness, we will run separate analyses for countries where respondents were clustered at different NUTS levels.

Given that the main purpose of this study is to identify the possible unique effects of individual generalised trust and contextual generalised trust, new measures have to be created to attain meaningful estimates. Technically, it is simple to model such within- and between-group effects simultaneously. The well-established procedure is known as group-mean centring, cluster-mean centring or centring within context (Raudenbush and Bryk 2002; Snijders and Bosker 1999: 52-56). The Level 1 predictor Trust $_{W i}$ is each respondent's deviation from the regional mean $\left(\right.$ Trust $\left._{i j}-\overline{\text { Trust }}_{. j}\right)$. An individual's level of generalised trust is now expressed relative to other respondents living in the same region. What group-mean centring does here is removing all between-region variation from the predictor and the regression coefficient will be a pure estimate of the Level 1-relationship between generalised trust and immigration attitudes. The Level 2 predictor Trust $_{B j}$ is each region's mean level of generalised trust $\left(\overline{\operatorname{Trust}}_{. j}\right)$.). Therefore, the Level 2 regression coefficient will inform us if and to what extent the contextual effect is at the regional level. In a raw score model without any centring, the regression coefficient for the raw score variable would be a weighted combination of the withinand between-group regression coefficients. Another statistical advantage of group-mean centring is that it removes all between-group variation from the Level 1 predictor. In fact, there is zero correlation between group-mean centred individual-level generalised trust and regional-level generalised trust.

\section{Control Variables}

First, we control for a set of standard demographic and socio-economic characteristics at the individual level. These are gender, age, years of education, unemployment and self-assessed household income. Second, we account for immigration background and immigrants in one's living environment. Three separate dummy variables capture if the respondent herself and her father and mother were born in another country. The variable neighbourhood diversity accounts for the perceived presence of people of minority race and ethnic groups (almost nobody, some and many). Friends of foreign origin asked if the respondent had close friends who are of different race or ethnic group (none at all, a few and several). Third, various attitudes are captured with questions on leftright position, internal efficacy (confident in own ability to participate in politics), external efficacy 
(politicians care what people think) and performance evaluations (satisfaction with the national economy). All responses were recorded on a scale from 0 to 10 .

In terms of education, numerous studies confirm that the lower educated hold more unfavourable attitudes towards immigration than higher educated citizens (Hainmueller and Hiscox 2007, of many) There are at least two possible explanations. First, in European countries where immigrants are, on average, less educated than the native population, natives with lower education may prefer limiting immigration if they fear a risk of growing labour market competition (Mayda, 2006). Second, educated individuals with more cognitive sophistication do not feel threatened by diversity and uncertainty that comes with interacting with strangers, because cognitive sophistication makes a more complex world easier to grasp (Herreros and Criado 2009; Voss et al. 2013; Yamagishi 2001). It may also be that educated individuals are more prone to give socially desirable answers to survey questions on immigration attitudes (Janus 2010). Previous studies also show that people with an optimistic view of their own financial situation as well as the state of the economy are more favourable towards immigration than those with a pessimistic view. The latter may feel that they are on the losing end if more applicants enter the labour market and benefit from the country's welfare (Citrin et al. 1997; Facchini et al. 2013).

Prior studies have shown that larger perceived immigrant presence may induce more anti-immigration attitudes, because natives may feel that they themselves are turning into a minority and, thus, losing their prerogatives (e.g. Quillian 1995). However, positive contact (such as friendship) with minorities has been shown to reduce negative perceptions (McLaren, 2003; Pettigrew and Tropp, 2011).

Givens and McGowen (2013) show that while there are significant differences in public opinion across left-right ideological positions in different countries, respondents who place themselves on the left are less likely to demonstrate intolerant views when it comes to immigration attitudes, ethnic minorities, and antidiscrimination policies. We also include indices of both external and internal political efficacy. It is expected that citizens who have difficulties in understanding political processes, who feel that their personal power to influence agenda setting is limited, and who feel alienated from mainstream political institutions perceive lack of control and are therefore less likely to accept immigrants (Pettigrew and Tropp, 2011, 152). 
Finally, at the contextual level, we control for whether people who live in regions that are economically depressed and have witnessed an increase in immigrant-origin population (group threat theory) are more likely to have anti-immigrant sentiments (Quillian 1995). Due to limited data availability, only three objective regional-level factors are included here as contextual controls. They represent predictors at different administrative levels: net migration (\%, mean 2010-2014) measured at the NUTS 3 level, non-European immigrants $(\%, 2011)$ at the NUTS 2 level and unemployment $(\%, 2011)$ at the NUTS 2. The regional-level indicators have been collected by Eurostat. Finally, country dummy variables are introduced to control for unobserved country-level factors. These dummy variables soak up any part of the variation in the dependent variable that can be accounted for by nationally shared values and experiences relating to cultural, historical, political and economic conditions.

\section{Method}

A multilevel statistical design, where individual responses (Level 1) are nested within regions (Level 2) nested within countries (Level 3), is used to rigorously test the hypotheses relating to the effect of individual-level generalised trust and the possible contextual effects of generalised trust on immigration attitudes. An important advantage of multilevel modelling is the ability to assess the effects of lower level and higher level variables simultaneously. Furthermore, multilevel models account for the clustering of observations. Measurements of outcomes from subjects within the same group are likely to be correlated. Multilevel models effectively handle the dependency of observations within groups and provide more precise estimates of fixed effects and standard errors (Raudenbush and Bryk, 2002; Snijders and Bosker, 1999, 52-56).

\section{Empirical Results}

We begin the discussion of our empirical results by describing how generalised trust aggregated at the regional level covaries with immigration attitudes. In Figure 1, each grey solid circle represents a region with mean trust on the $\mathrm{x}$-axis plotted against the mean immigration attitudes score on the $\mathrm{y}$ axis. The lines represent the linear fit between regional trust and pro-immigration attitudes. A total of 247 regions in 20 countries are included in the analysed sample. The average number of regions per country is 12.4 with a range between five (Denmark, Estonia and Portugal) and 21 regions (France 
and Sweden). Two small Spanish regions with less than ten respondents each have been removed in order to be certain that they do not bias the results. 

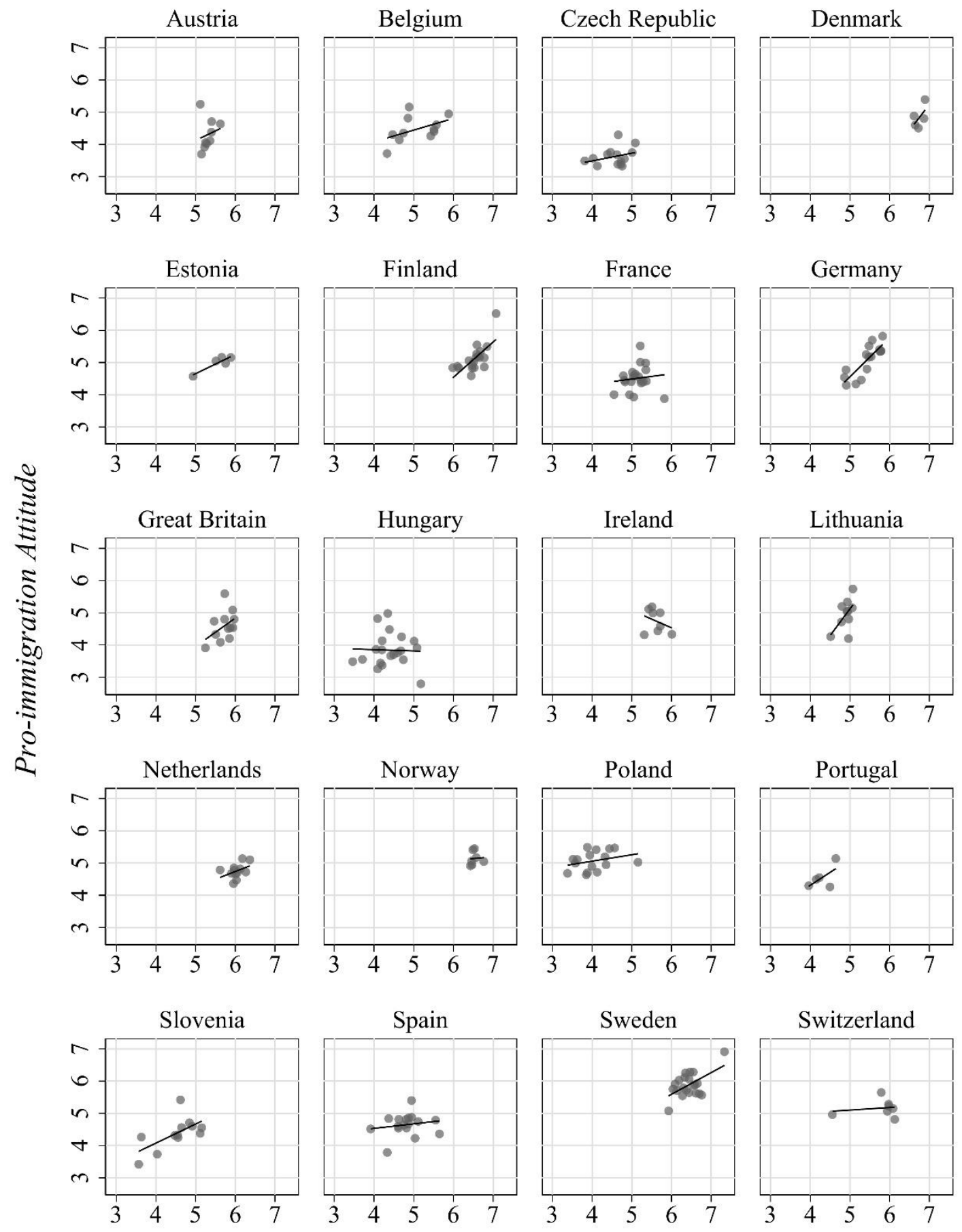

Regional Trust

Figure 1. Relationship between regional trust and immigration attitudes by country. 
First, the country plots demonstrate that there is considerable variation in regional trust within countries. On average, the difference between the minimum and maximum values for regional generalised trust within countries is 1.1 points. Second, the slopes of the lines are positive in most countries. For example, the strongest correlations between regional trust and immigration attitudes are found in Germany, Finland, Estonia, Portugal and Slovenia with correlations over 0.62. Exceptions are France, Hungary, Ireland and Norway where the correlation coefficient is negative or below +0.11 . If all regions are pooled into a single sample, the correlation is moderate to strong $(\mathrm{r}=$ $0.56, \mathrm{p}<0.01, \mathrm{~N}=247)$. Hence, at first sight the graphs suggest that individuals who live in regions with higher mean levels of generalised trust exhibit more positive attitudes towards immigration. Yet, we cannot be sure if collective properties have an effect on immigration attitudes, over and above the effect of individual citizen characteristics, nor can we be certain whether the regional context or the country context is more decisive.

Let us now turn to the evidence regarding our three hypotheses. The results of the multilevel linear regressions are presented in Table 1 . Model 1 is a random intercept model, meaning that we allow the intercepts between countries and regions to vary. Model 2 is a random-intercept-and-slopes model where we allow the slope of the Level 1 predictor generalised trust to be random at Level 2 (i.e. the individual-level effect of generalised trust on immigration attitudes may vary between regions). The random-intercept-and-slopes model significantly reduces the deviance in comparison with the simpler fixed slope model whereby there is a model improvement. Model 3 adds the cross-level interaction and reduces the deviance, although by a small amount. All models include country fixed effects (i.e. country dummy variables) whereby all country-specific factors are absorbed into the country fixed effects. Controlling for any unobservable characteristics at the country level allows us to explicitly focus on variations between individuals and between regions.

Overall, the individual-level controls behave as expected. In terms of the three contextual variables, net migration and unemployment are statistically insignificant. The coefficient for the third contextual variable, i.e. number of non-European immigrants, is positive and has a statistically significant impact. However, the effect is very weak. Going from 0 to a 10 per cent share of non-European immigrants in the region equals a mere increase of 0.2 points in favourability to immigrants. Given the weak effect, we cannot with confidence say that the result is against the group threat theory, which 
predicts that presence of visible minority groups may trigger negative out-group assessments. ${ }^{1}$ Neighbourhood diversity has a non-linear effect. Respondents who describe they live in an area with some people of ethnic minority groups are more positive towards immigrants than those who live in an area with almost no ethnic minority groups, while those who live in an area with many ethnic groups exhibit negative attitudes towards immigrants. Also, having friends of foreign origin increases pro-immigration attitudes.

${ }^{1}$ The unexpected positive effect with respect to non-European immigrants could be a result of not measuring a change in status quo. If the regional share of non-European immigrants has remained stable, the context is likely not to appear threatening. 
Table 1. Predicting pro-immigration attitudes: multilevel linear regression.

\begin{tabular}{|c|c|c|c|}
\hline & Model 1 & Model 2 & Model 3 \\
\hline & Est (SE) & Est (SE) & Est (SE) \\
\hline \multicolumn{4}{|l|}{ Fixed effects } \\
\hline Intercept & $3.18(0.11)^{* *}$ & $3.19(0.11)^{* *}$ & $3.19(0.11)^{* *}$ \\
\hline \multicolumn{4}{|l|}{ Generalised trust } \\
\hline Individual & $0.19(0.01)^{* *}$ & $0.19(0.01)^{* *}$ & $0.19(0.01)^{* *}$ \\
\hline Region & $0.22(0.09)^{*}$ & $0.20(0.09)^{*}$ & $0.19(0.08)^{*}$ \\
\hline Individual $\times$ Region & - & - & $0.02(0.01)^{*}$ \\
\hline \multicolumn{4}{|l|}{ Control variables } \\
\hline Female & $0.02(0.04)$ & $0.02(0.04)$ & $0.02(0.04)$ \\
\hline Age/10 & $-0.00(0.02)$ & $-0.00(0.02)$ & $-0.00(0.02)$ \\
\hline Years of education/10 & $0.47(0.05)^{* *}$ & $0.47(0.05)^{* *}$ & $0.47(0.05)^{* *}$ \\
\hline Unemployed: $>3$ months & $0.01(0.04)$ & $0.00(0.04)$ & $0.00(0.04)$ \\
\hline Unemployed: No & $0.02(0.03)$ & $0.02(0.03)$ & $0.02(0.03)$ \\
\hline Income: Difficult & $0.25(0.05)^{* *}$ & $0.26(0.05)^{* *}$ & $0.26(0.05)^{* *}$ \\
\hline Income: Coping & $0.36(0.06)^{* *}$ & $0.36(0.06)^{* *}$ & $0.36(0.06)^{* *}$ \\
\hline Income: Living comfortably & $0.47(0.06)^{* *}$ & $0.47(0.06)^{* *}$ & $0.47(0.06)^{* *}$ \\
\hline Respondent born outside country & $0.21(0.06)^{* *}$ & $0.21(0.06)^{* *}$ & $0.21(0.06)^{* *}$ \\
\hline Father born outside country & $0.21(0.03)^{* *}$ & $0.21(0.03)^{* *}$ & $0.21(0.03)^{* *}$ \\
\hline Mother born outside country & $0.22(0.04)^{* *}$ & $0.21(0.04)^{* *}$ & $0.21(0.04)^{* *}$ \\
\hline Neighbourhood diversity: Some & $0.06(0.02)^{* *}$ & $0.07(0.02)^{* *}$ & $0.07(0.02)^{* *}$ \\
\hline Neighbourhood diversity: Many & $-0.14(0.04)^{* *}$ & $-0.13(0.04)^{* *}$ & $-0.13(0.04)^{* *}$ \\
\hline Friends of foreign origin: A few & $0.34(0.04)^{* *}$ & $0.33(0.04)^{* *}$ & $0.33(0.04)^{* *}$ \\
\hline Friends of foreign origin: Several & $0.69(0.07)^{* *}$ & $0.69(0.07)^{* *}$ & $0.69(0.07)^{* *}$ \\
\hline Left-Right: $0-2$ & $0.75(0.12)^{* *}$ & $0.74(0.12)^{* *}$ & $0.74(0.12)^{* *}$ \\
\hline Left-Right: $3-4$ & $0.66(0.10)^{* *}$ & $0.65(0.10)^{* *}$ & $0.65(0.10)^{* *}$ \\
\hline Left-Right: 5 & $0.37(0.08)^{* *}$ & $0.37(0.08)^{* *}$ & $0.37(0.08) * *$ \\
\hline Left-Right: 6-7 & $0.29(0.06)^{* *}$ & $0.28(0.06)^{* *}$ & $0.28(0.06)^{* *}$ \\
\hline Left-Right: Don't know & $0.36(0.09)^{* *}$ & $0.35(0.09)^{* *}$ & $0.35(0.09)^{* *}$ \\
\hline External efficacy & $0.09(0.01)^{* *}$ & $0.09(0.01)^{* *}$ & $0.09(0.01)^{* *}$ \\
\hline Internal efficacy & $0.05(0.00)^{* *}$ & $0.05(0.00)^{* *}$ & $0.05(0.00)^{* *}$ \\
\hline Satisfaction with the economy & $0.12(0.01)^{* *}$ & $0.12(0.01)^{* *}$ & $0.12(0.01)^{* *}$ \\
\hline Net migration & $-0.01(0.01)$ & $-0.00(0.01)$ & $-0.01(0.01)$ \\
\hline Non-European immigrants & $0.02(0.01)^{* *}$ & $0.02(0.01)^{* *}$ & $0.02(0.01)^{* *}$ \\
\hline Unemployment & $0.00(0.01)$ & $-0.00(0.01)$ & $0.00(0.01)$ \\
\hline Country-fixed effects & Yes & Yes & Yes \\
\hline \multicolumn{4}{|l|}{ Random effects } \\
\hline Level-1 residual variance & $1.980(0.084)$ & $1.964(0.101)$ & $1.964(0.092)$ \\
\hline Level-2 intercept variance & $0.049(0.013)$ & $0.050(0.013)$ & $0.050(0.067)$ \\
\hline Level-2 slope variance & - & $0.006(0.005)$ & $0.006(0.003)$ \\
\hline Level-2 intercept-slope covariance & - & $-0.004(0.003)$ & $-0.004(0.019)$ \\
\hline Level-3 intercept variance & $0.000(0.000)$ & $0.000(0.000)$ & $0.000(0.000)$ \\
\hline Deviance & 115,704 & 115,601 & 115,594 \\
\hline
\end{tabular}

Notes: Model 1 is a random intercepts model and Models 2 and 3 are random-intercept-and-slopes models. 33,062 individuals are nested in 247 regions nested in 20 countries. Reference categories are male, unemployed for more than 12 months, very difficult living on present income, respondent not born outside country, father not born outside country, mother not born outside country, almost nobody belong to a minority race/ethnic group in the neighbourhood, no close friends of different race or ethnic group and 8-10 on the Left-Right scale.

$* * \mathrm{p}<0.01 ; * \mathrm{p}<0.05$. 
We first examine if respondents with high individual generalised trust demonstrate more positive immigration attitudes. Our data support Hypothesis 1. The coefficient for the individual-level generalised trust variable is substantially and statistically significant in Model 1. For a one-unit change in generalised trust, pro-immigrant attitudes increase by 0.19 points. This is a substantial effect given the large variation in the variable. The individual-level (within-region) predictor, which is centred on the regional mean, varies from -6.89 to 5.90 with a mean of zero and a standard deviation of 1.65. Hence, the advantage of group-mean centring the predictor is that we are able to model the pure individual-level effect of generalised trust that is not confounded with contextual-level effects.

We do not find support for Hypothesis 2, which predicted that high contextual trust leads to more positive immigration attitudes. In other words, it does not appear that contextual trust explains unique variance in the dependent variable, over and beyond the effect of the same predictor at the individual level. We come to this conclusion by comparing the magnitudes of the within-group and betweengroup coefficients (Feaster et al., 2011). Since group-mean centring is applied, the interpretation of the coefficients is different from traditional models. For a regional contextual effect on immigration attitudes to be present in our statistical model, the coefficient for the contextual predictor should be significantly larger in magnitude than the individual-level predictor. Only then can we infer that the contextual-level generalised trust gives an additional contribution over and above the effect of individual-level generalised trust (Raudenbush and Bryk, 2002, 139-141; Snijders and Bosker, 1999, 52-56). We simply calculate the difference between the within- and between-group effects based on the regression coefficients using the formula $\beta_{\mathrm{B}}-\beta_{\mathrm{W}}$. Since the coefficient for regional trust is only marginally higher in magnitude compared to the individual-level trust (i.e. $0.22-0.19=0.03$ ), there is no regional contextual effect. A test of the equality of the between-region within-country and within-region coefficients confirms that we cannot reject the hypothesis that $\beta_{\mathrm{B}}=\beta_{\mathrm{W}}\left(\chi^{2}=0.10, \mathrm{p}=\right.$ $0.75) .^{2}$

Hence, the analysis here failed to show a general relationship between contextual trust and proimmigrant attitudes by examining multiple countries and regions. In Online Appendix A, we have run country-by-country analyses to detect possible differences between countries. The results show that the coefficient for regional-level generalised trust is larger than the coefficient for individual-

\footnotetext{
${ }^{2}$ Another way to demonstrate that there is no contextual effect is to run a regression model where the raw score for the generalized trust index ( 0 to 10$)$ is included instead of the deviation from the regional mean. In such a model, the coefficient for the raw score for the trust index (0.19) is identical to the coefficient for within-region variable in Model 3, Table 2 . In contrast, the coefficient for the regional mean coefficient is 0.03 and statistically insignificant $(\mathrm{p}=0.72)$.
} 
level generalised trust in 11 of 20 countries. However, tests of the equality of coefficients indicate that the contextual effect is positive and significant in only four countries (Austria, Estonia, Finland and Netherlands). This implies that there is no general positive contextual effect. Neither does there appear to be any geographic clusters of countries where the contextual effect is stronger. Furthermore, in Online Appendix B, C and D we ran separate analyses for countries where respondents were clustered at different NUTS levels. The results do not imply that context effect surfaces more forcefully in the cluster of NUTS 3 regions (i.e. lowest administrative level) in Appendix D compared to the clusters at the NUTS 1 and NUTS 2 levels.

Finally, in line with Hypothesis 3, the effect of individual-level generalised trust on immigration attitudes varies according to the contextual level of trust. Hence, a second method for identifying contextual effects is by adding cross-level interactions (Feaster et al., 2011), in our case by interacting individual-level trust with the regional generalised trust. Model 3 in Table 1 shows that the coefficient of the interaction variable is positive $(\beta=0.02)$ and statistically significant $(p<0.05)$. This suggests that the effect of individual-level trust is reinforced (i.e. sunmaker effect) when the surrounding level of generalised trust is also high. To better grasp how substantial the interaction effect is, we present marginal effects and predictive margins plots.

Figure 2 shows how the marginal effect of individual-level trust varies according to variation in trust between regions. The marginal effect slope is positive: the higher the regional mean, the greater the positive effect of individual-level trust on immigration attitudes. The effect (i.e. how much a one-unit change in generalised trust affects pro-immigrant attitudes) increases from 0.15 to 0.24 going from the lowest to highest observed value for regional-level generalised trust. Thus, a high-trusting regional context encourages high-trusting people to develop even more positive attitudes towards immigrants. This reinforcement effect is also evident from the predictive margins plot in Figure 3 where the values for the individual-level predictor is set to two standard deviations above and below the regional mean. The gap in immigrant attitudes between low- and high-trusting individuals $(-2$ and +2 standard deviations from the mean) in the least trusting region is about 0.96 points. The same gap in the most trusting region is about 1.58 points. 


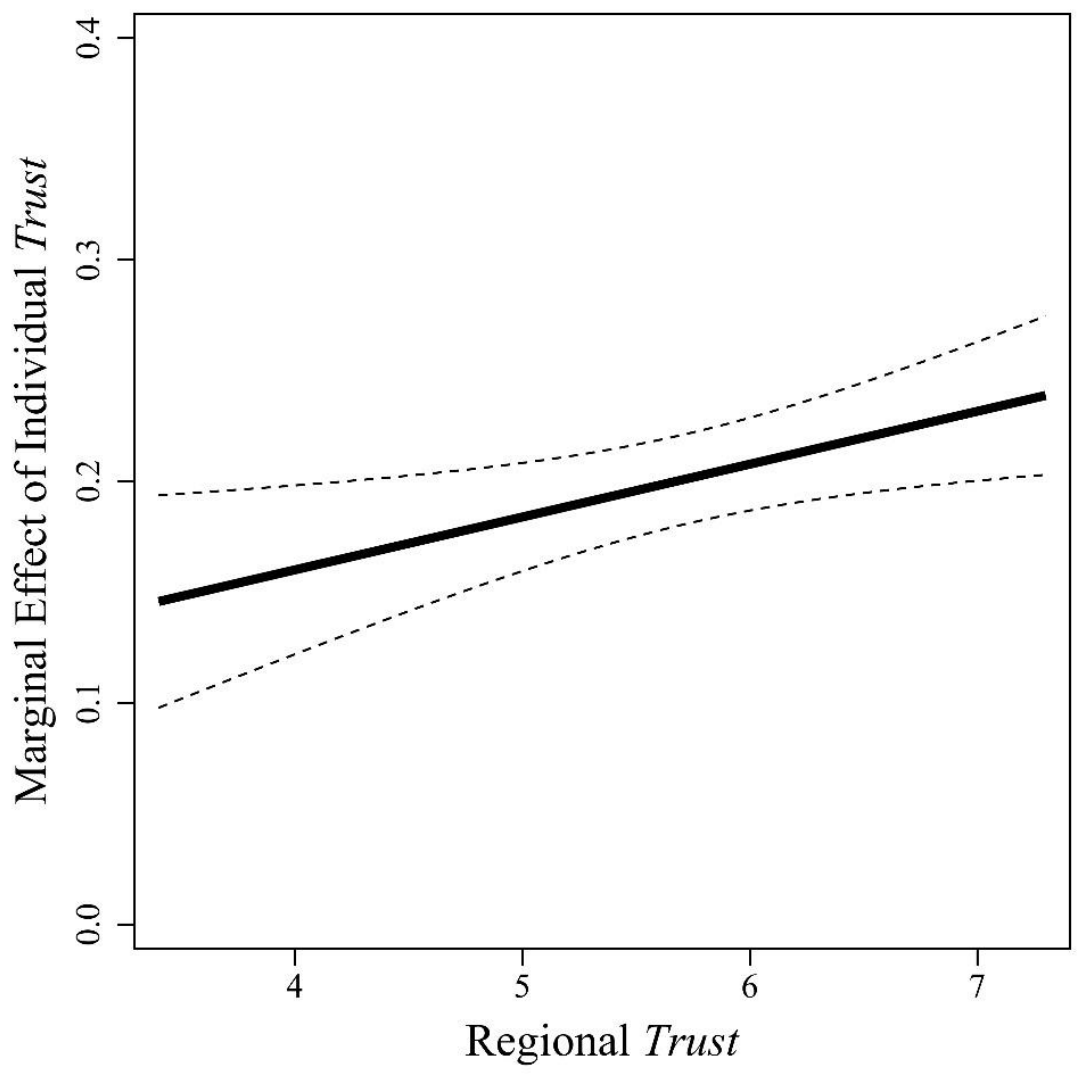

Figure 2. Marginal effect of individual trust on immigration attitudes by regional trust (with 95 percent confidence intervals). 


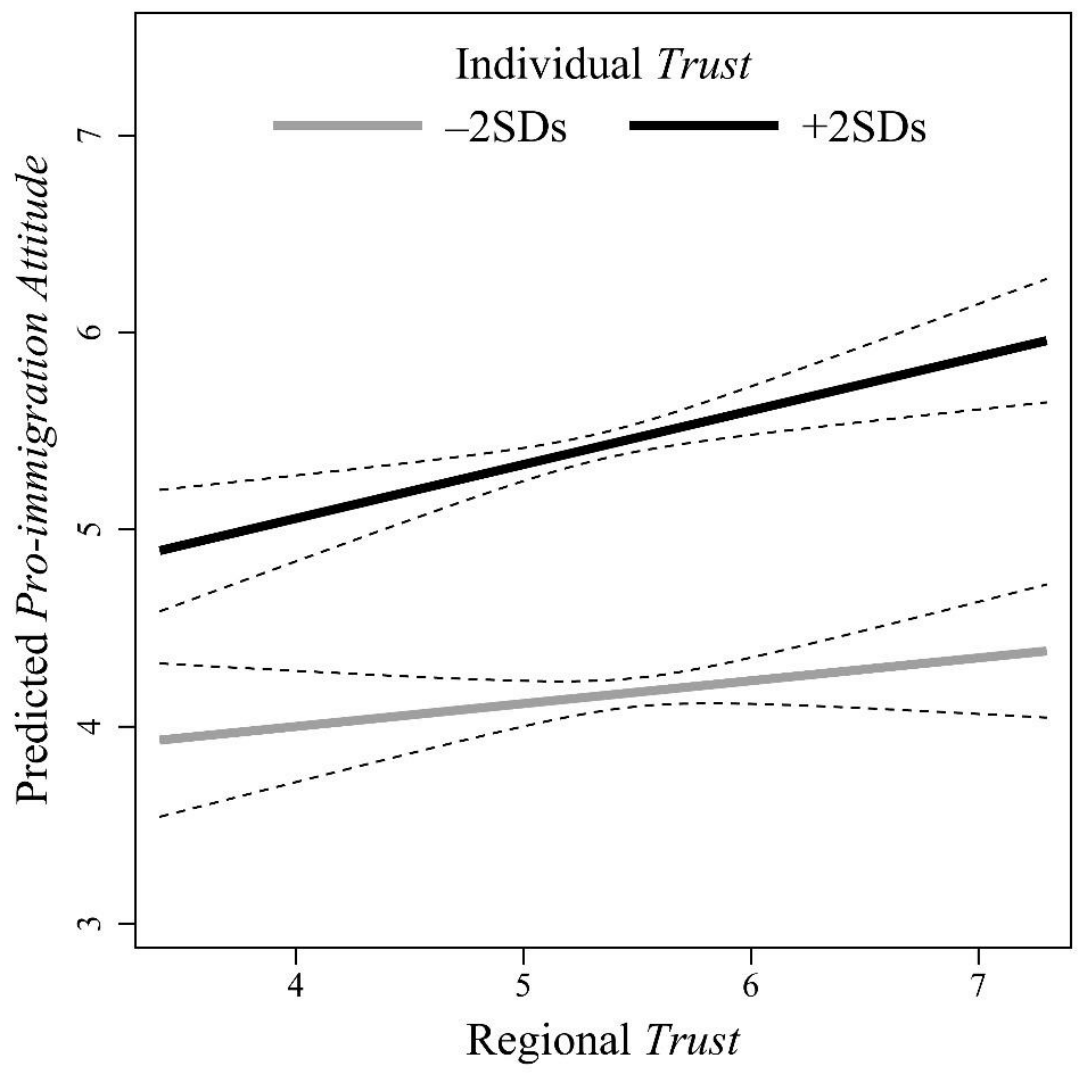

Figure 3. Predicted immigration attitudes by regional trust when individual trust is set two standard deviations below and above the mean (with 95 percent confidence intervals).

\section{Conclusions}

Generalised trust, or faith in strangers, is a value that promotes interaction between people unknown to each other. Its value is constantly growing in importance as countries that have developed into welfare societies during the past century now need to share their welfare with new citizens of foreign origin. In this article, we have examined whether generalised trust has the ability to reduce negative immigration attitudes. Indeed, cross-national individual data from the European Social Survey (2014/2015) indicate that citizens who trust "most people in general" are less inclined to think that immigrants threaten their welfare, culture or their own opportunities for a good life. They feel that their country is generally enriched by immigrants and that immigrants will contribute to society rather than live off social benefits. Generalised trusters prevent the society from splitting into groups that only foster particularised trust (Uslaner 2002: 191). 
However, the data show that there is no unique contextual effect. Generalised trust aggregated at the regional level did not make an additional contribution over and above the effect of individual-level generalised trust. In other words, living in a high-trust context does not, by itself, encourage positive attitudes towards immigrants. On the other hand, another type of contextual effect seems to be present. The effect of the individual's level of generalised trust on pro-immigrant attitudes varies by the level of regional generalised trust. This is a reinforcement effect: a high-trusting regional context encourages high-trusting people in particular to develop even more positive attitudes towards immigrants. This is an interesting empirical finding that calls for further studies about the workings of contextual trust. While it appears that the idea of Putnam et al. (1993: 177) about a "virtuous circle" does involve those individuals who are already trusting, our analyses suggest that such a virtuous circle does not come to reach those who are less trusting and make their attitudes towards immigration more positive.

Having said that, we acknowledge that there are a number of limitations to this study. It is an observational study based on cross-sectional data that are collected at a single time point. Crosssectional estimates can be subject to substantial upward bias. Also, we cannot be fully convinced that the identified links are causal. Our greatest concern is omitted variable bias, which arises if unmeasured variables are correlated with both the independent variable of interest and the outcome variable. Examples of confounding variables are innate psychological traits or personal experiences that influence both generalised trust and immigrant attitudes. There is also the possibility that people's repeated interaction with immigrants stimulates both pro-immigrant attitudes and generalised trust. In that case, generalised trust does not precede immigrant attitudes, but both are caused by social interaction. We controlled for a range observed characteristics both at the individual and contextual levels. The set of controls included the presence of immigrants in the broader geographic unit, ethnic diversity in the immediate area of living and having immigrants in the respondents' social circles (family and friends). Yet, overall, it cannot be completely ruled out that we were unable to include underlying third variables - particularly contextual factors - that could have either revealed that some relationships were spurious or that some relationships were concealed.

High aggregate-level trust is closely linked to other societal characteristics that may affect the relationship between trust and perceptions on immigration at the individual level. For instance, high democratic and institutional stability, as well as economic prospects, are arguably important factors 
when the population becomes more diverse. Moreover, some countries and regions are more affected by immigration than others, and it could be expected that this has consequences on the social and welfare systems in these countries. Europe has also seen a rise in support for populist right-wing parties in many countries. While these parties, depending on their electoral success, have varying influence in governmental policies, they do have the ability to affect the public opinion. Interestingly, and somewhat discouragingly, societies with high generalised trust have also witnessed increased support for populist parties with anti-immigration agenda and, thus, seem to be equally affected by populism as countries with lower general levels of trust (Koivula et al. 2017: 1033-1034). Social trust both at the individual and neighbourhood-level has, however, been found to decrease radical rightwing populist party preferences (Berning and Ziller 2017). Thus, while it is likely that the effects of generalised social trust are positive, both at the individual and the societal levels, a more difficult question is how it can be developed and maintained in societies with increased immigration and diversity.

\footnotetext{
${ }^{1}$ Our main conclusions are robust to the exclusion of respondents with any missing values on the immigration attitudes index. $\mathrm{N}$ would drop from 30,062 to 29,915 by excluding respondents with one or two missing values. The coefficient for individual generalized trust would remain 0.19 , while the coefficient for regional generalized trust would decrease from 0.20 to 0.17 (see Model 2 in Table 1). The coefficient for the interaction variable (individual trust $\times$ regional trust) would also be 0.02 (as in Model 3 in Table 1).
} 


\section{References}

Allport, G. W. (1955) The Nature of Prejudice, Cambridge: Addison-Wesley.

Bäck, M. and Christensen, H. S. (2016) 'When trust matters: a multilevel analysis of the effect of generalised trust on political participation in 25 European democracies', Journal of Civil Society 12: 178-97.

Berning, C. C. and Ziller, C. (2017) 'Social trust and radical right-wing populist party preferences', Acta Politica 52: 198-217.

Blalock, H. M. (1967) Toward a Theory of Minority-Group Relations, New York: Wiley.

Bobo, L. (1983) 'Whites' opposition to busing: symbolic racism or realistic group conflict?', Journal of Personality and Social Psychology 45: 1196-210.

Borjas, G. J. (2001) Heaven's Door: Immigration Policy and the American Economy, Princeton: Princeton University Press.

Brewer, M. B. (2001) 'Ingroup identification and intergroup conflict: when does ingroup love become outgroup hate?' in R. D. Ashmore, L. Jussim and D. Wilder (eds.), Social Identity, Intergroup Conflict, and Conflict Reduction, New York: Oxford University Press, pp. 17-41.

Citrin, J., Green, D. P., Muste, C. and Wong, C. (1997) 'Public opinion toward immigration reform: the role of economic motivations', The Journal of Politics 59: 858-81.

Dinesen, P. and Søderskov, K. (2018) 'Ethnic diversity and social trust: a critical review of the literature and suggestions for a research agenda', in E. Uslaner (ed.), The Oxford Handbook of Social and Political Trust, Oxford: Oxford University Press, pp. 175-204.

Facchini, G., Mayda, A. M. and Puglisi, R. (2013) 'Individual attitudes towards immigration: economic vs. non-economic determinants', in G. P. Freeman, R. Hansen and D. L. Leal (eds.), Immigration and Public Opinion in Liberal Democracies, London: Routledge, pp. 129-57.

Feaster, D., Brincks, A., Robbins, M. and Szapocznik, J. (2011) 'Multilevel models to identify contextual effects on individual group member outcomes: a family example', Family Process 50: $167-83$.

Freeman, G. P., Hansen, R. and Leal, D. L. (2013) Immigration and Public Opinion in Liberal Democracies, London: Routledge.

Givens, T. E. and McGowen, E. (2013) 'Party politics and public opinion on immigration and antidiscrimination policy', in G. P. Freeman, R. Hansen and D. L. Leal (eds.), Immigration and Public Opinion in Liberal Democracies, London: Routledge, pp. 271-85.

Hainmueller, J. and Hiscox, M. J. (2007) 'Educated preferences: explaining attitudes toward immigration in Europe', International Organization 61: 399-442.

Hainmueller, J. and Hiscox, M. J. (2010) 'Attitudes toward highly skilled and lowskilled immigration: evidence from a survey experiment', American Political Science Review 104: 61-84.

Hardin, R. (2001) 'Conceptions and explanations of trust', in K. S. Cook (ed.), Trust in Society, New York: Russel Sage Foundation, pp. 3-39.

Herreros, F. (2004) The Problem of Forming Social Capital: Why Trust?, New York: Palgrave Macmillan. 
Herreros, F. and Criado, H. (2009) 'Social trust, social capital and perceptions of immigration', Political Studies 57: 337-55.

Janus, A. L. (2010) 'The influence of social desirability pressures on expressed immigration attitudes', Social Science Quarterly 91: 928-46.

Koivula, A., Saarinen, A. and Räsänen, P. (2017) 'Political party preference and social trust in four Nordic countries', Comparative European Politics 15: 1030-51.

Markaki, Y. and Longhi, S. (2013) 'What determines attitudes to immigration in European countries? An analysis at the regional level', Migration Studies 1: 311-337.

Mayda, A. M. (2006) 'Who is against immigration? A cross-country investigation of individual attitudes toward immigrants', Review of Economics and Statistics 88: 510-30.

McLaren, L. M. (2003) 'Anti-immigrant prejudice in Europe: contact, threat perception, and preferences for the exclusion of migrants', Social Forces 81: 909-36.

Messick, D. M. and Kramer, R. M. (2001) 'Trust as a form of shallow morality', in K. S. Cook (ed.), Trust in Society, New York: Russel Sage Foundation, pp. 89-117.

Newton, K. (1999) 'Social capital and democracy in modern Europe', in M. Maraffi, K. Newton, J. van Deth and P. Whiteley (eds.), Social Capital and European Democracy, London: Routledge, pp. 3-24.

Newton, K. (2001) 'Trust, social capital, civil society, and democracy', International Political Science Review 22: 201-214.

Paxton, P. (2007) 'Association memberships and generalised trust: a multilevel model across 31 countries', Social Forces 86: 47-76.

Pettigrew, T. F. and Tropp, L. R. (2011) When Groups Meet: Dynamics of Intergroup Contact, New York: Psychology Press.

Putnam, R. D, Pharr, S. J. and Dalton R. J. (2000) 'What's troubling the trilateral democracies?' in R. D. Putnam and S. J. Pharr (eds.), Disaffected Democracies: What's Troubling the Trilateral Countries? Princeton: Princeton University Press, pp. 3-30.

Putnam, R. D., Leonardi, R. and Nanetti, R. Y. (1993) Making Democracy Work: Civic Traditions in Modern Italy, Princeton: Princeton University Press.

Quillian, L. (1995) 'Prejudice as a response to perceived group threat: population composition and anti-immigrant and racial prejudice in Europe', American Sociological Review 60: 586-611.

Raudenbush, S. W. and Bryk, A. S. (2002) Hierarchical Linear Models: Applications and Data Analysis Method, Thousand Oaks: Sage.

Reeskens, T. (2013) 'But who are those "most people" that can be trusted? Evaluating the radius of trust across 29 European societies', Social Indicators Research 114: 703-22.

Rothstein, B. and Uslaner, E. (2005) 'All for all: equality, corruption, and social trust', World Politics 58: $41-72$.

Rustenbach, E. (2010) 'Sources of negative attitudes toward immigrants in Europe: A multi-level analysis', International Migration Review 44: 53-77. 
Sherif, M. and Sherif, C. W. (1979) 'Research on intergroup relations', in W. G. Austin and S. Worchel (eds.), The Social Psychology of Intergroup Relations, Monterey: Brooks/Cole, pp. $7-$ 18.

Snijders, T. A. B. and Bosker, R. J. (1999) Multilevel Analysis: An Introduction to Basic and Advanced Multilevel Modeling, London: Sage.

Stephan, W. G. and Stephan, C. W. (2000) 'An integrated threat theory of prejudice', in S. Oskamp (ed.), Reducing Prejudice and Discrimination, Mahwah: Lawrence Erlbaum Associates, pp. 234.

Stephan, W. G., Lausanne Renfro, C., Esses, V. M., White Stephan, C. and Martin, T. (2005) 'The effects of feeling threatened on attitudes toward immigrants', International Journal of Intercultural Relations 29: 1-19.

Stolle, D. (2001) 'Clubs and congregations: the benefits of joining an association', in K. S. Cook (ed.), Trust in Society, New York: Russel Sage Foundation, pp. 202-44.

Stolle, D. (2002) 'Trusting strangers: the concept of generalised trust in perspective', Österreichische Zeitschrift Für Politikwissenschaft 31: 397-412.

Tajfel, H. and Turner, J. C. (1979) 'An integrative theory of intergroup conflict', in W. G. Austin and S. Worchel (eds.), The Social Psychology of Intergroup Relations, Monterey: Brooks/Cole, pp. $33-47$.

Uslaner, E. (2002) The Moral Foundations of Trust, Cambridge: Cambridge University Press.

Uslaner, E. (2010) ‘Segregation, mistrust and minorities', Ethnicities 10: 415-34.

Uslaner, E. (2012) Segregation and Mistrust: Diversity, Isolation, and Social Cohesion, Cambridge: Cambridge University Press.

van der Linden, M., Hooghe, M., de Vroome, T. and Van Laar, C. (2017) 'Extending trust to immigrants: generalised trust, cross-group friendship and anti-immigrant sentiments in 21 European societies', PLoS One 12:e177369.

van der Meer, J. (2003) 'Rain or fog? An empirical investigation of social capital's rainmaker effects', in M. Hooghe and D. Stolle (eds.), Generating Social Capital: Civil Society and Institutions in Comparative Perspective, New York: Palgrave Macmillan, pp. 133-51.

Voss, D. S., Kehrberg, J. E. and Butz, A. M. (2013) 'The structure of self-interest(s): applying comparative theory to U.S immigration attitudes', in G. P Freeman, R. Hansen and D. L. Leal (eds.), Immigration and Public Opinion in Liberal Democracies, London: Routledge, pp. 93125 .

Yamagishi, T. (2001) 'Trust as a form of social intelligence', in K. S. Cook (ed.), Trust in Society, London: Routledge, pp. 121-47.

Zmerli, S., Newton, K. and Montéro, J. R. (2007) 'Trust in people, confidence in political institutions, and satisfaction with democracy', in J. W. van Deth, J. R. Montero and A. Westholm (eds.), Citizenship and Involvement in European Democracies: A Comparative Analysis, London and New York: Routledge, pp. 35-65. 
Online Appendix A. Country-by-country analyses of the effects on individual-level and regionallevel generalised trust on immigrant attitudes.

\begin{tabular}{|c|c|c|c|}
\hline Country & Generalised trust & Est (SE) & $\beta_{\mathrm{B}}-\beta_{\mathrm{W}}$ Sig \\
\hline \multirow[t]{2}{*}{ Austria } & Individual & $0.21(0.04)^{* *}$ & \\
\hline & Region & $1.45(0.30)^{* *}$ & $1.24 \chi^{2}=17.56, p<0.01$ \\
\hline \multirow[t]{2}{*}{ Great Britain } & Individual & $0.25(0.04)^{* *}$ & \\
\hline & Region & $0.69(0.25)^{* *}$ & $0.44 \chi^{2}=2.74, p=$ n.s. \\
\hline \multirow[t]{2}{*}{ Estonia } & Individual & $0.19(0.03)^{* *}$ & \\
\hline & Region & $0.62(0.10)^{* *}$ & $0.43 \chi^{2}=19.64, p<0.01$ \\
\hline \multirow[t]{2}{*}{ Portugal } & Individual & $0.21(0.04)^{* *}$ & \\
\hline & Region & $0.61(0.10)^{* *}$ & $0.40 \chi^{2}=9.52, p<0.01$ \\
\hline \multirow[t]{2}{*}{ Netherlands } & Individual & $0.20(0.02)^{* *}$ & \\
\hline & Region & $0.60(0.19)^{* *}$ & $0.40 \chi^{2}=4.02, p<0.05$ \\
\hline \multirow[t]{2}{*}{ Finland } & Individual & $0.19(0.04)^{* *}$ & \\
\hline & Region & $0.46(0.18)^{*}$ & $0.27 \chi^{2}=2.11, p=$ n.s. \\
\hline \multirow[t]{2}{*}{ Slovenia } & Individual & $0.20(0.04)^{* *}$ & \\
\hline & Region & $0.41(0.13)^{* *}$ & $0.21 \chi^{2}=2.24, p=$ n.s. \\
\hline \multirow[t]{2}{*}{ Germany } & Individual & $0.21(0.02)^{* *}$ & \\
\hline & Region & $0.40(0.19)^{*}$ & $0.19 \chi^{2}=0.89, p=$ n.s. \\
\hline \multirow[t]{2}{*}{ Czech Republic } & Individual & $0.09(0.02)^{* *}$ & \\
\hline & Region & $0.25(0.11)^{*}$ & $0.16 \chi^{2}=1.76, p=$ n.s. \\
\hline \multirow[t]{2}{*}{ Switzerland } & Individual & $0.17(0.03)^{* *}$ & \\
\hline & Region & $0.31(0.52)$ & $0.14 \chi^{2}=0.08, p=$ n.s. \\
\hline \multirow[t]{2}{*}{ Lithuania } & Individual & $0.19(0.02)^{* *}$ & \\
\hline & Region & $0.89(0.69)$ & $0.70 \chi^{2}=1.06, p=$ n.s. \\
\hline \multirow[t]{2}{*}{ France } & Individual & $0.29(0.04)^{* *}$ & \\
\hline & Region & $0.22(0.26)$ & $-0.07 \chi^{2}=0.07, p=$ n.s. \\
\hline \multirow[t]{2}{*}{ Poland } & Individual & $0.09(0.04)^{*}$ & \\
\hline & Region & $0.00(0.18)$ & $-0.09 \chi^{2}=0.24, p=$ n.s. \\
\hline \multirow[t]{2}{*}{ Sweden } & Individual & $0.16(0.03)^{* *}$ & \\
\hline & Region & $0.05(0.28)$ & $-0.11 \chi^{2}=0.14, p=$ n.s. \\
\hline \multirow[t]{2}{*}{ Spain } & Individual & $0.25(0.02)^{* *}$ & \\
\hline & Region & $0.04(0.21)$ & $-0.21 \chi^{2}=1.08, p=$ n.s. \\
\hline \multirow[t]{2}{*}{ Belgium } & Individual & $0.23(0.03)^{* *}$ & \\
\hline & Region & $-0.09(0.53)$ & $-0.32 \chi^{2}=0.35, p=$ n.s. \\
\hline \multirow[t]{2}{*}{ Hungary } & Individual & $0.13(0.04)^{* *}$ & \\
\hline & Region & $-0.29(0.34)$ & $-0.42 \chi^{2}=1.64, p=$ n.s. \\
\hline \multirow[t]{2}{*}{ Norway } & Individual & $0.22(0.04)^{* *}$ & \\
\hline & Region & $-0.23(0.74)$ & $-0.45 \chi^{2}=0.35, p=$ n.s. \\
\hline \multirow[t]{2}{*}{ Ireland } & Individual & $0.13(0.04)^{* *}$ & \\
\hline & Region & $-1.50(0.24)^{* *}$ & $-1.63 \chi^{2}=37.59, p<0.01$ \\
\hline \multirow[t]{2}{*}{ Denmark } & Individual & $0.22(0.03)^{* *}$ & \\
\hline & Region & $-2.91(0.50)^{* *}$ & $-3.13 \chi^{2}=36.42, p<0.01$ \\
\hline
\end{tabular}

Notes: A two-level multilevel regression model (individuals nested within regions) was run for each country separately. For brevity, neither the coefficients on control variables nor random effects components are reported. $\beta_{\mathrm{B}}-\beta_{\mathrm{W}}$ is the difference between the coefficient for regional-level generalised trust and individual-level generalised trust, followed by a significance test of equality of the coefficients. $* * \mathrm{p}<0.01 ; * \mathrm{p}<0.05$. 
Online Appendix B. Predicting pro-immigration attitudes where respondents are clustered at the NUTS 1 level.

\begin{tabular}{|c|c|c|}
\hline & Model 1 & Model 2 \\
\hline & Est (SE) & Est (SE) \\
\hline \multicolumn{3}{|l|}{ Fixed effects } \\
\hline Intercept & $3.23(0.29)^{* *}$ & $3.23(0.29)^{* *}$ \\
\hline \multicolumn{3}{|l|}{ Generalised trust } \\
\hline Individual & $0.23(0.02)^{* *}$ & $0.22(0.02)^{* *}$ \\
\hline Region & $0.73(0.23)^{* *}$ & $0.74(0.23)^{* *}$ \\
\hline Individual $\times$ Region & - & $0.03(0.01)^{*}$ \\
\hline \multicolumn{3}{|l|}{ Control variables } \\
\hline Female & $-0.08(0.01)^{* *}$ & $-0.08(0.01)^{* *}$ \\
\hline Age/10 & $-0.01(0.05)$ & $-0.01(0.05)$ \\
\hline Years of education/10 & $0.65(0.04)^{* *}$ & $0.65(0.04)^{* *}$ \\
\hline Unemployed: $>3$ months & $-0.01(0.12)$ & $-0.01(0.12)$ \\
\hline Unemployed: No & $0.04(0.06)$ & $0.04(0.06)$ \\
\hline Income: Difficult & $0.43(0.22)$ & $0.43(0.22)$ \\
\hline Income: Coping & $0.67(0.04)^{* *}$ & $0.67(0.04)^{* *}$ \\
\hline Income: Living comfortably & $0.73(0.07)^{* *}$ & $0.73(0.07)^{* *}$ \\
\hline Respondent born outside country & $0.18(0.23)$ & $0.18(0.23)$ \\
\hline Father born outside country & $0.16(0.02)^{* *}$ & $0.16(0.02)^{* *}$ \\
\hline Mother born outside country & $0.27(0.15)$ & $0.27(0.15)$ \\
\hline Neighbourhood diversity: Some & $0.05(0.02)^{*}$ & $0.05(0.02)^{*}$ \\
\hline Neighbourhood diversity: Many & $-0.08(0.00)^{* *}$ & $-0.08(0.00)^{* *}$ \\
\hline Friends of foreign origin: A few & $0.16(0.05)^{* *}$ & $0.16(0.05)^{* *}$ \\
\hline Friends of foreign origin: Several & $0.50(0.01)^{* *}$ & $0.50(0.01)^{* *}$ \\
\hline Left-Right: $0-2$ & $1.31(0.01)^{* *}$ & $1.31(0.01)^{* *}$ \\
\hline Left-Right: $3-4$ & $1.16(0.01)^{* *}$ & $1.16(0.01)^{* *}$ \\
\hline Left-Right: 5 & $0.76(0.14)^{* *}$ & $0.76(0.14)^{* *}$ \\
\hline Left-Right: $6-7$ & $0.51(0.10)^{* *}$ & $0.51(0.10)^{* *}$ \\
\hline Left-Right: Don't know & $0.67(0.23)^{* *}$ & $0.67(0.23)^{* *}$ \\
\hline External efficacy & $0.09(0.01)^{* *}$ & $0.09(0.01)^{* *}$ \\
\hline Internal efficacy & $0.06(0.01)^{* *}$ & $0.06(0.01)^{* *}$ \\
\hline Satisfaction with the economy & $0.15(0.01)^{* *}$ & $0.15(0.01)^{* *}$ \\
\hline Net migration & $-0.00(0.04)$ & $-0.00(0.04)$ \\
\hline Non-European immigrants & $0.02(0.01)^{*}$ & $0.02(0.01)^{*}$ \\
\hline Unemployment & $0.03(0.00)^{* *}$ & $0.03(0.00)^{* *}$ \\
\hline Country-fixed effects & Yes & Yes \\
\hline \multicolumn{3}{|l|}{ Random effects } \\
\hline Level-1 residual variance & $2.037(0.434)$ & $2.037(0.434)$ \\
\hline Level-2 intercept variance & $0.020(0.012)$ & $0.020(0.011)$ \\
\hline Level-2 slope variance & $0.003(0.005)$ & $0.003(0.005)$ \\
\hline Level-2 intercept-slope covariance & $0.001(0.003)$ & $0.001(0.003)$ \\
\hline Level-3 intercept variance & $0.000(0.000)$ & $0.000(0.000)$ \\
\hline Deviance & 16,974 & 16,974 \\
\hline
\end{tabular}

Notes: 4,835 individuals nested in 28 regions nested in 2 countries.

$* * \mathrm{p}<0.01 ; * \mathrm{p}<0.05$. 
Online Appendix C. Predicting pro-immigration attitudes where respondents are clustered at the NUTS 2 level.

\begin{tabular}{|c|c|c|}
\hline & Model 3 & Model 4 \\
\hline & Est (SE) & Est (SE) \\
\hline \multicolumn{3}{|l|}{ Fixed effects } \\
\hline Intercept & $3.15(0.16)^{* *}$ & $3.15(0.16)^{* *}$ \\
\hline \multicolumn{3}{|l|}{ Generalised trust } \\
\hline Individual & $0.21(0.02)^{* *}$ & $0.22(0.01)^{* *}$ \\
\hline Region & $0.14(0.08)$ & $0.13(0.08)$ \\
\hline Individual $\times$ Region & - & $0.01(0.02)$ \\
\hline \multicolumn{3}{|l|}{ Control variables } \\
\hline Female & $-0.07(0.04)^{* *}$ & $-0.07(0.04)^{* *}$ \\
\hline Age/10 & $0.03(0.01)^{* *}$ & $0.03(0.01)^{* *}$ \\
\hline Years of education/10 & $0.46(0.05)^{* *}$ & $0.46(0.05)^{* *}$ \\
\hline Unemployed: $>3$ months & $-0.01(0.04)$ & $-0.01(0.04)$ \\
\hline Unemployed: No & $-0.01(0.04)$ & $-0.01(0.04)$ \\
\hline Income: Difficult & $0.20(0.10)^{*}$ & $0.20(0.10)^{*}$ \\
\hline Income: Coping & $0.29(0.12)^{*}$ & $0.29(0.12)^{*}$ \\
\hline Income: Living comfortably & $0.38(0.12)^{* *}$ & $0.38(0.12)^{* *}$ \\
\hline Respondent born outside country & $0.30(0.07)^{* *}$ & $0.30(0.07)^{* *}$ \\
\hline Father born outside country & $0.17(0.05)^{* *}$ & $0.17(0.05)^{* *}$ \\
\hline Mother born outside country & $0.24(0.06)^{* *}$ & $0.24(0.06)^{* *}$ \\
\hline Neighbourhood diversity: Some & $0.11(0.03)^{* *}$ & $0.11(0.03)^{* *}$ \\
\hline Neighbourhood diversity: Many & $-0.09(0.06)$ & $-0.09(0.06)$ \\
\hline Friends of foreign origin: A few & $0.33(0.03)^{* *}$ & $0.33(0.03)^{* *}$ \\
\hline Friends of foreign origin: Several & $0.72(0.09)^{* *}$ & $0.73(0.09)^{* *}$ \\
\hline Left-Right: $0-2$ & $0.88(0.13)^{* *}$ & $0.88(0.14)^{* *}$ \\
\hline Left-Right: $3-4$ & $0.79(0.10)^{* *}$ & $0.79(0.10)^{* *}$ \\
\hline Left-Right: 5 & $0.48(0.08)^{* *}$ & $0.48(0.08)^{* *}$ \\
\hline Left-Right: $6-7$ & $0.35(0.08)^{* *}$ & $0.35(0.08)^{* *}$ \\
\hline Left-Right: Don't know & $0.38(0.11)^{* *}$ & $0.37(0.12)^{* *}$ \\
\hline External efficacy & $0.09(0.01)^{* *}$ & $0.09(0.01)^{* *}$ \\
\hline Internal efficacy & $0.04(0.01)^{* *}$ & $0.04(0.01)^{* *}$ \\
\hline Satisfaction with the economy & $0.12(0.01)^{* *}$ & $0.12(0.01)^{* *}$ \\
\hline Net migration & $0.01(0.01)^{*}$ & $0.01(0.01)^{*}$ \\
\hline Non-European immigrants & $0.02(0.01)^{* *}$ & $0.02(0.01)^{* *}$ \\
\hline Unemployment & $-0.01(0.00)$ & $-0.01(0.00)$ \\
\hline Country-fixed effects & Yes & Yes \\
\hline \multicolumn{3}{|l|}{ Random effects } \\
\hline Level-1 residual variance & $1.843(0.104)$ & $1.843(0.117)$ \\
\hline Level-2 intercept variance & $0.030(0.001)$ & $0.030(0.026)$ \\
\hline Level-2 slope variance & $0.005(0.002)$ & $0.005(0.002)$ \\
\hline Level-2 intercept-slope covariance & $-0.010(0.003)$ & $-0.009(0.003)$ \\
\hline Level-3 intercept variance & $0.000(0.000)$ & $0.000(0.000)$ \\
\hline Deviance & 50,967 & 50,966 \\
\hline
\end{tabular}

Notes: 14,883 individuals nested in 110 regions nested in 10 countries.

** $\mathrm{p}<0.01 ; * \mathrm{p}<0.05$. 
Online Appendix D. Predicting pro-immigration attitudes where respondents are clustered at the NUTS 3 level.

\begin{tabular}{|c|c|c|}
\hline & Model 5 & Model 6 \\
\hline & Est (SE) & Est (SE) \\
\hline \multicolumn{3}{|l|}{ Fixed effects } \\
\hline Intercept & $3.15(0.26)^{* *}$ & $3.15(0.26)^{* *}$ \\
\hline \multicolumn{3}{|l|}{ Generalised trust } \\
\hline Individual & $0.16(0.01)^{* *}$ & $0.16(0.01)^{* *}$ \\
\hline Region & $0.23(0.15)$ & $0.23(0.15)$ \\
\hline Individual $\times$ Region & - & $0.03(0.01)^{* *}$ \\
\hline \multicolumn{3}{|l|}{ Control variables } \\
\hline Female & $0.17(0.05)^{* *}$ & $0.17(0.05)^{* *}$ \\
\hline Age/10 & $-0.04(0.03)$ & $-0.04(0.03)$ \\
\hline Years of education/10 & $0.42(0.12)^{* *}$ & $0.42(0.12)^{* *}$ \\
\hline Unemployed: $>3$ months & $0.01(0.09)$ & $0.01(0.09)$ \\
\hline Unemployed: No & $0.05(0.08)$ & $0.05(0.08)$ \\
\hline Income: Difficult & $0.26(0.06)^{* *}$ & $0.26(0.06)^{* *}$ \\
\hline Income: Coping & $0.34(0.07)^{* *}$ & $0.35(0.07)^{* *}$ \\
\hline Income: Living comfortably & $0.48(0.07)^{* *}$ & $0.48(0.07)^{* *}$ \\
\hline Respondent born outside country & $0.14(0.11)$ & $0.14(0.11)$ \\
\hline Father born outside country & $0.28(0.06)^{* *}$ & $0.28(0.06)^{* *}$ \\
\hline Mother born outside country & $0.15(0.06)^{*}$ & $0.15(0.06)^{*}$ \\
\hline Neighbourhood diversity: Some & $0.04(0.03)$ & $0.04(0.03)$ \\
\hline Neighbourhood diversity: Many & $-0.19(0.08)^{*}$ & $-0.19(0.08)^{*}$ \\
\hline Friends of foreign origin: A few & $0.40(0.08)^{* *}$ & $0.40(0.08)^{* *}$ \\
\hline Friends of foreign origin: Several & $0.71(0.14)^{* *}$ & $0.71(0.14)^{* *}$ \\
\hline Left-Right: $0-2$ & $0.42(0.21)^{*}$ & $0.42(0.21)^{*}$ \\
\hline Left-Right: $3-4$ & $0.33(0.15)^{*}$ & $0.33(0.15)^{*}$ \\
\hline Left-Right: 5 & $0.15(0.13)$ & $0.15(0.13)$ \\
\hline Left-Right: 6-7 & $0.16(0.10)$ & $0.16(0.10)$ \\
\hline Left-Right: Don't know & $0.17(0.12)$ & $0.17(0.12)$ \\
\hline External efficacy & $0.08(0.01)^{* *}$ & $0.08(0.01)^{* *}$ \\
\hline Internal efficacy & $0.04(0.01)^{* *}$ & $0.04(0.01)^{* *}$ \\
\hline Satisfaction with the economy & $0.10(0.01)^{* *}$ & $0.10(0.01)^{* *}$ \\
\hline Net migration & $-0.02(0.01)$ & $-0.01(0.01)$ \\
\hline Non-European immigrants & $0.01(0.01)$ & $0.01(0.01)$ \\
\hline Unemployment & $0.00(0.01)$ & $0.00(0.01)$ \\
\hline Country-fixed effects & Yes & Yes \\
\hline \multicolumn{3}{|l|}{ Random effects } \\
\hline Level-1 residual variance & $2.026(0.123)$ & $2.025(0.121)$ \\
\hline Level-2 intercept variance & $0.069(0.031)$ & $0.069(0.034)$ \\
\hline Level-2 slope variance & $0.004(0.002)$ & $0.004(0.003)$ \\
\hline Level-2 intercept-slope covariance & $0.000(0.012)$ & $0.000(0.005)$ \\
\hline Level-3 intercept variance & $0.000(0.000)$ & $0.000(0.000)$ \\
\hline Deviance & 47,236 & 47,231 \\
\hline
\end{tabular}

Notes: 13,344 individuals nested in 109 regions nested in 8 countries.

$* * \mathrm{p}<0.01 ; * \mathrm{p}<0.05$. 